\section{Evaluation of protective effect of hydroalcoholic extract of saffron petals in prevention of acetaminophen-induced renal damages in rats}

\author{
Arash Omidi,1 Narges Riahinia,2 \\ Mohammad Bagher Montazer Torbati,2 \\ Mohammad Ali Behdani3
}

1Animal Health Management Department, School of Veterinary Medicine, Shiraz University; ${ }^{2}$ Animal Science Department, Agriculture Faculty, Birjand University; 3Saffron Research Group, Birjand University, Iran

\section{Abstract}

In recent years more attention has been given to herbal drugs in the treatment and prevention of drug toxicity because of the harmful effects of chemical drugs. In this study, directed for this purpose, research was conducted on the protective effect of hydro-ethanolic extract of saffron petals (SPE) against acetaminophen (APAP) induced acute nephrotoxicity. Twentyfour male Wistar rats were distributed into four groups of six each. Group I, as a control group, received normal saline $(0.09 \%)$ orally (P0). Group II, as an intoxicated group was treated with APAP, PO $(600 \mathrm{mg} / \mathrm{kg})$. In the groups III and IV, SPE in a dose of 10 and 20 $\mathrm{mg} / \mathrm{kg}$ along with APAP (600 $\mathrm{mg} / \mathrm{kg}$ ) was administered, respectively. At the end of the trial (8th day), blood was taken from the heart of rats for assessment of biochemical parameters and the right kidney was placed in $10 \%$ buffered formalin for histopathological evaluations. In the APAP treatment group, higher serum creatinine and uric acid were observed. SPE in a dose of $20 \mathrm{mg} / \mathrm{kg}$ significantly reduced serum creatinine and uric acid. In pathologic evaluation, a dose of $20 \mathrm{mg} / \mathrm{kg}$ of SPE prevented the kidney injuries induced by APAP. Tissues changes were in accordance with biochemical findings. It is likely that the SPE contributed to the prevention of acute nephrotoxicity induced by APAP.

\section{Introduction}

Acetaminophen (APAP or paracetamol), chemically named N-acetyl-p-aminophenol, is a widely used nonprescription analgesic and antipyretic medication. Use of APAP in therapeutic doses is safe. APAP is rapidly and almost completely absorbed from the gastrointestinal tract, but overdose of the drug leads to lifethreatening or fatal hepatic necrosis and renal failure. ${ }^{1} \mathrm{APAP}$ is now the most common drug in self-poisoning, with a high rate of morbidity and mortality. ${ }^{2}$ Many cases of poisoning with APAP in humans and animals have been reported.3-7 Nephrotoxicity is less common than hepatotoxicity, but acute renal failure is possible, even in the absence of liver damage. Renal failure can occur even with therapeutic doses. ${ }^{8}$ Renal effects of APAP have received less attention. Administration of $\mathrm{N}$-acetyle cycstein (NAC) is used to treat APAP-induced hepatotoxicity but glutathione is more effective than NAC in preventing liver injury. ${ }^{9}$ NAC leads to increased hepatic glutathione, but is not able to protect the kidney against APAP.10 Moreover, it must be noted that conjugates of glutathione have been implicated in the formation of nephrotoxic compounds. 11 Uric acid is an end product of the metabolism of purine through the action of xanthine dehydrogenase or xanthine oxidase. Serum uric acid can be elevated due to reduced excretion by the kidney. Creatinine is produced from creatine, a molecule of major importance for energy production in muscles. Low clearance values for creatinine indicate a diminished ability of the kidneys to filter waste products from the blood. As clearance levels of kidneys for excretion in the urine decrease, blood levels of uric acid and creatinine increase. ${ }^{12,13}$ Several plants reported to contain antioxidant compounds act as hepatoprotective.14-16 Saffron (Crocus sativus L.) is one of the most important and valuable herbs of Iran. Saffron is a perennial stemless herb with numerous medical properties used in traditional medicine. ${ }^{17}$ Beneficial effects of saffron in the treatment or prevention of kidney disorders have been noted. ${ }^{18,19}$ Various pharmacological studies have been done on saffron by researchers. Some effects such as anticonvulsants, antihypertensives, ${ }^{20}$ antinociceptive and anti-inflammatory, ${ }^{21}$ antidepressants, ${ }^{22}$ antimicrobial, ${ }^{23}$ anticancer and chemopreventive agent, ${ }^{24,25}$ free radical scavenging, 18 and the prevention of cisplatininduced nephrotoxicity using the stigma of saffron have been mentioned. 26

Positive linear correlation was noted between the phenolic content and antioxidant capacity of the medicinal herbs. ${ }^{27}$ Saffron petals are a rich source of flavonoids that can be potentially used as an antioxidant compound in pharmaceutical research.28,29 Flavonoids are powerful antioxidants and prevent DNA damages. ${ }^{30}$ Saffron petals are one of the easily accessible sources of natural antioxidants and several of them are obtained during the saffron processing. Several studies have shown that the saffron petals have a large variety of flavonoid compounds, glycosides and anthocyanins. ${ }^{31}$ The concentration of $500 \mathrm{ppm}$ of extract of saffron petals (SPE) is equal to a
Correspondence: Arash 0midi, Department of Animal Health Management, School of Veterinary Medicine, Shiraz University, Shiraz, Iran. Tel.: +98.711.613.8745 - Fax: +98.711.228.6940. E-mail: arashomidi2@yahoo.com

Key words: Acetaminophen; rat; renal toxicity; saffron petals.

Contributions: the authors contributed equally.

Conflict of interest: the authors declare no potential conflict of interest.

Received for publication: 21 January 2015.

Revision received: 4 March 2015.

Accepted for publication: 10 March 2015.

This work is licensed under a Creative Commons Attribution NonCommercial 3.0 License (CC BYNC 3.0).

(C) Copyright A. Omidi et al., 2015

Licensee PAGEPress srl, Italy

Veterinary Science Development 2015; 5:5821

doi:10.4081/vsd.2015.5821

synthetic antioxidant (TBHQ) at the level of 100 ppm in vitro. ${ }^{32}$ Antioxidants can neutralize free radicals in the environment and prevent the damaging effects of them. According to the available resources, effect of SPE in the prevention or treatment of nephrotoxicity induced by APAP has not been studied. SPE has been shown to be protective against APAP induced liver necrosis. 16 This observation prompted us to study whether SPE protects against APAP induced renal damage.

\section{Materials and Methods}

\section{Animals}

Twenty-four Wistar rats weighing $220 \pm 20 \mathrm{~g}$ were individually housed in $25 \times 22 \times 20 \mathrm{~cm}$ stainless steel cages in the standard rat house $\left(22-25^{\circ} \mathrm{C}\right.$ on a $12 \mathrm{~h}$ light-dark cycle) and were fed on a pellet diet (Javaneh Khorasan Co, Mashhad, Iran). The rats had free access to food and distilled water.

\section{Animal ethics}

All the rats received humane care in accordance with the approval of Institutional Ethics Committee rules of the Agriculture Faculty of Birjand University. Also, the recommendations of European Council Directive (86/609/EC) of November 24,1986 , regarding the standards in the protection of animals used for experimental purposes were followed. 


\section{Preparing the petal extract}

Saffron was collected from Hajiabad Village (Kashmar) in Khorasan-Razavi province, northeast Iran, in December 2012 (Figure 1) and the samples were identified by the Agricultural Faculty of Birjand University in Iran. The voucher number of specimen (No. 2669) was deposited in the herbarium of Birjand University as well. To prepare the SPE, the samples were dried in shade and then pulverized with a grinder (Hamilton Beach Brand, Canada). Hydroalcoholic extract of SPE was prepared using $50 \mathrm{~g}$ of dried powder in 1000 $\mathrm{mL}$ of $80 \% \mathrm{v} / \mathrm{v}$ ethanol and shaking for $24 \mathrm{~h}$. The mixture was filtered through a No. 1 Whatman filter paper and then oven-dried at $40^{\circ} \mathrm{C}$ for 24 hours. The yield (w/w) was $30 \%$ after the final powdered extract was weighed and calculated.

\section{Treatment schedule}

One week after the adaptation period, rats were divided into 4 groups of 6 animals. Experimental groups include: Group I: received $5 \mathrm{ml}$ normal saline $(0.9 \% \mathrm{NaCl})$ daily by gavage method for 7 days. Group II: received $5 \mathrm{ml}$ normal saline $(0.9 \% \mathrm{NaCl})$ daily for 6 days. On the $7^{\text {th }}$ day rats in this group received APAP (600 $\mathrm{mg} / \mathrm{kg}$ ) by gavage method. Group III: received low dose of SPE $(10 \mathrm{mg} / \mathrm{kg})$ daily for 6 days. On the $7^{\text {th }}$ day the rats received APAP $(600 \mathrm{mg} / \mathrm{kg})$ by gavage method. Group IV: received high dose of SPE $(20 \mathrm{mg} / \mathrm{kg})$ daily for 6 days. On the $7^{\text {th }}$ day they received APAP $(600 \mathrm{mg} / \mathrm{kg})$ by gavage method. The SPE doses were selected based on the previous reports and pilot studies. ${ }^{29}$ SPE was dissolved in normal saline and the pure powder of APAP was dissolved in 20\% alcohol, while all the solutions were administered by oral gavage. After 24 hours of APAP intoxication, rats were euthanized by ether and then sacrificed.

\section{Biochemical and histopathological analysis}

The blood sample was collected by cardiac puncture and the serums separated by centrifugation of the samples at $750 \mathrm{~g}$ for $15 \mathrm{~min}$ at room temperature, they were then stored at $-21^{\circ} \mathrm{C}$ for further analysis. The concentration of creatinine was determined by the Jaffé method. ${ }^{33}$ Colorimetry and uricase method were used to measure uric acid level (Uric acid TOOS kit, Pars Azmoon Co, Iran). After necropsy, the right kidney was removed and fixed in $10 \%$ formalin buffer at room temperature. After fixing the tissue, it was thoroughly washed under running water and dehydrated in ascending grades of ethyl alcohol, cleared afterwards and embedded in soft paraffin. Tissue sections of about $5 \mu \mathrm{m}$ were obtained, and stained by hematoxylin and eosin (H\&E), then observed under a light microscope. ${ }^{34}$

\section{Statistical analysis}

All the tested parameters were subjected to statistical analysis which was done by One-way Analysis of Variance (ANOVA) and means were compared by Dunnett's comparison. The level of significance was set at $\mathrm{P}<0.05$.

\section{Results}

Biochemical results obtained from measurements of creatinine and uric acid are shown in Figure 2. In rats that received the toxic dose of APAP, creatinine and uric acid levels were significantly increased compared with the control group. The results showed that both doses of 10 and $20 \mathrm{mg} / \mathrm{kg}$ of SPE significantly decreased cre-

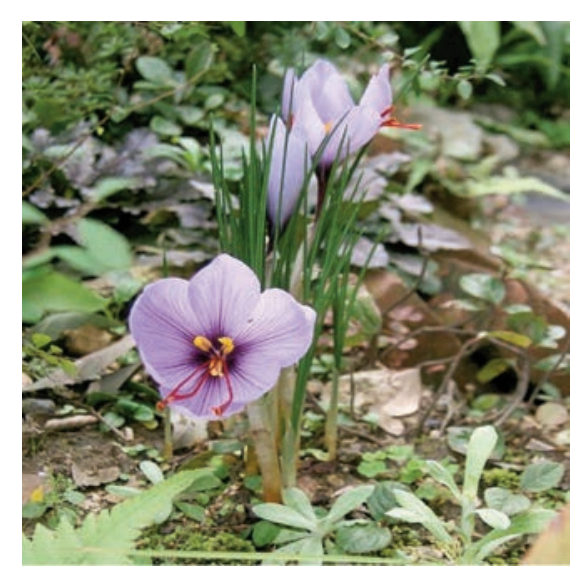

Figure 1. Purple colored petal of saffron (Crocus sativus).

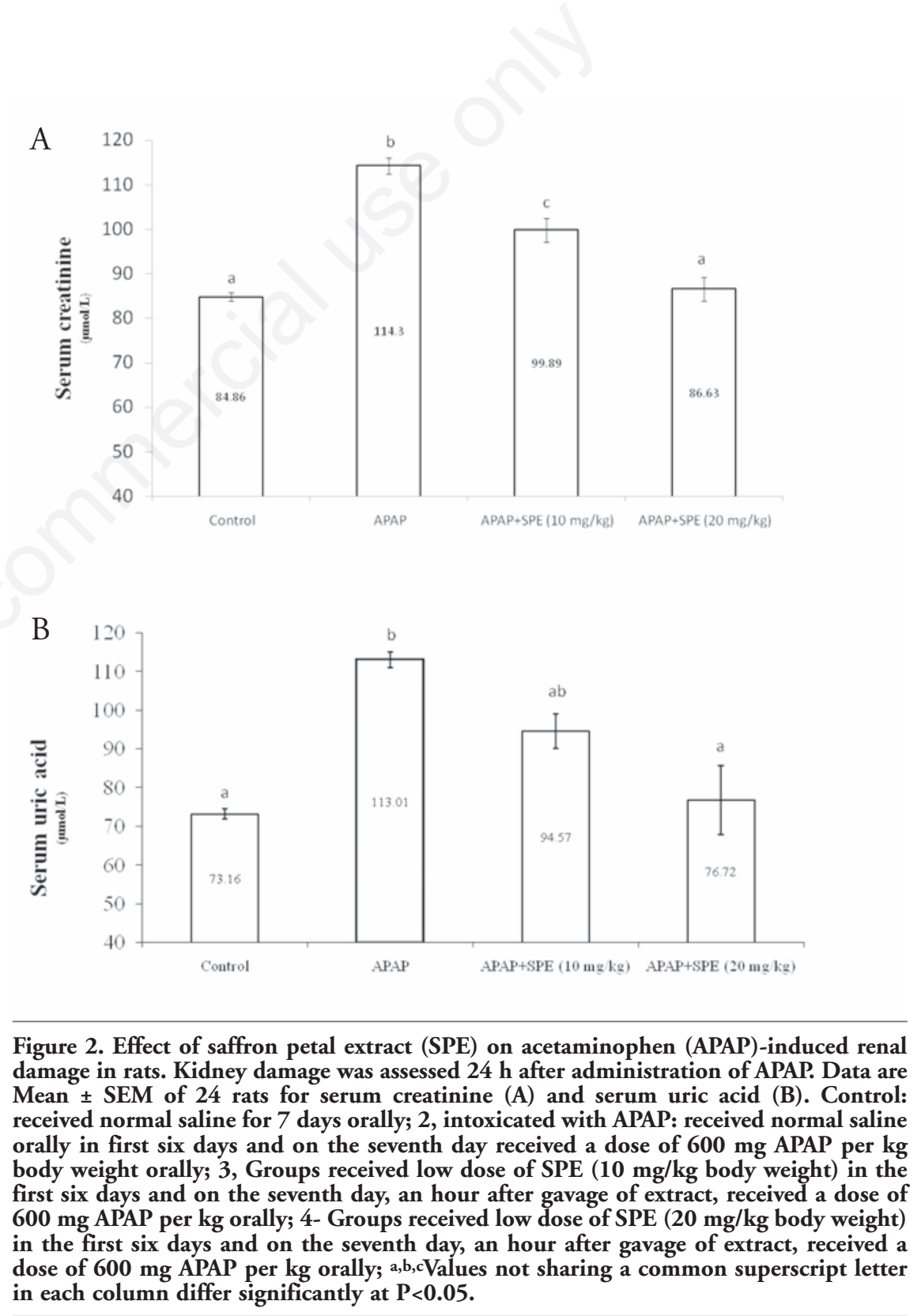


atinine levels compared with APAP, but the reduction by dose of $20 \mathrm{mg} / \mathrm{kg}$ was more. High dose of SPE (20 mg/kg) significantly decreased elevated levels of serum uric acid caused by APAP $(\mathrm{P}<0.05)$. Low dose of SPE $(10 \mathrm{mg} / \mathrm{kg})$ reduced elevated serum levels of uric acid numerically. Rats that received APAP had severe kidney damage such as glomerular and tubular necrosis, interstitial tubular nephrosis and inflammation in the kidney. However, when the SPE was combined with APAP, kidney damages were less than in the case of APAP alone. In rats that received normal saline, normal kidney tissue appearance was observed (Figure 3A). In rats that received APAP alone, evidence of necrosis and impaired renal glomeruli, tubules and interstitial tissue were seen (Figure 3B). In rats that received a toxic dose of APAP along with low doses of SPE (10 mg/kg), kidney damage was less severe than the intoxicated rats. Hyaline casts and mild interstitial nephritis were observed in this group (Figure 3C). In rats treated with a high dose of SPE (20 mg/kg), histologic appearance of the kidney was almost similar to the normal kidney. Tubules necrosis and impaired renal glomeruli were considered insignificant (Figure 3D).
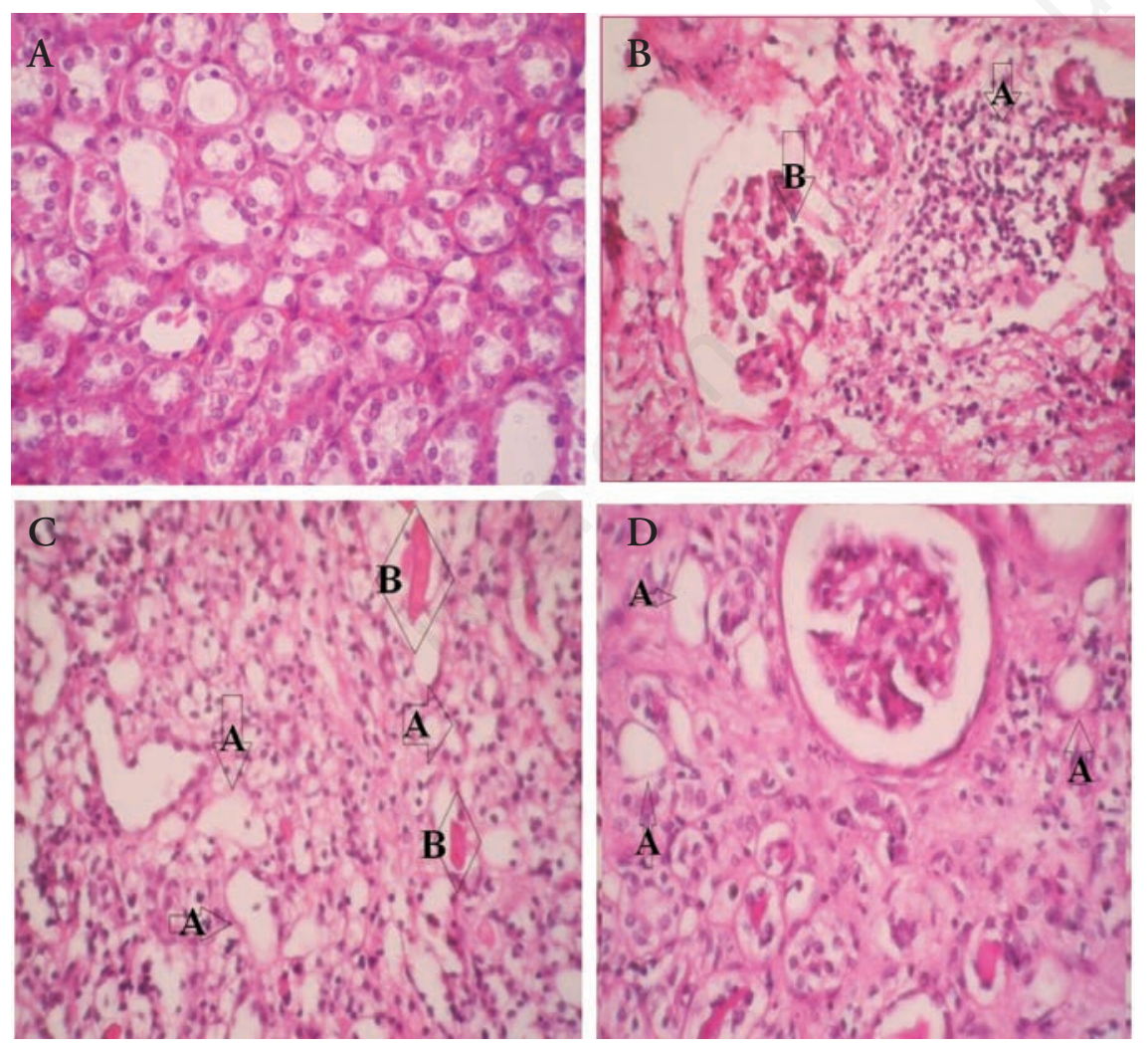

Figure 3. A) Light microscopic appearance of the rat kidney of the healthy rat; normal renal proximal and distal tubules are seen; B) light microscopic appearance of the rat kidney of poisoned rat; interstitial nephritis (arrow $A$ ) and glomerulonephritis (arrow B) are seen; C) light microscopic appearance of the kidney of a poisoned rat treated with low dose of saffron petal extract (SPE), $(10 \mathrm{mg} / \mathrm{kg})$; mild interstitial nephritis (arrow A) and hyaline casts (arrow B) are seen; D) light microscopic appearances of the kidney of a poisoned rat treated with high dose of saffron petal extract (SPE), $(20 \mathrm{mg} / \mathrm{kg})$; mild necrosis in renal tubules (arrow $A)$ are seen $(H \& E$ stain, $40 \times)$. to be involved in APAP-induced renal toxicity such as cytochrome P-450 enzymes, glutathione S-transferase, prostaglandin endoperoxidase synthase (PGES), N-deacetylase, tumor necrosis factor (TNF)- $\alpha$ and oxidative stress. ${ }^{38,39}$ NAC protects against APAP hepatotoxicity, but is unable to protect against APAP nephrotoxicity. ${ }^{40}$ The results show that a dose of $20 \mathrm{mg} / \mathrm{kg}$ of SPE had a better protective effect than dose of $10 \mathrm{mg} / \mathrm{kg}$. In the present study, histopathological findings also indicate renal interstitial necrosis and severe damage to the glomeruli and tubules by APAP. Slight glomerular and tubular damages were seen in prescription of SPE along with APAP and there was no evidence of necrosis. The findings of the present study indicate a protective effect of SPE against nephrotoxicity induced by APAP. Different pharmacological effects have been seen from saffron and its active constituents. Inhibition of oxidative stress induced by free radical oxygen species and increased glutathione synthesis could be mentioned in the reduction and prevention of acute toxicity and renal tubular damages caused by cisplatin. ${ }^{41}$ It has been shown that the stigma of saffron has protective effect against gentamicin-induced nephrotoxicity in rats. ${ }^{42}$ Also, it has been shown in mice that the extract of saffron stigma has a protective effect on the liver tissue against the effects of rifampin. ${ }^{43}$ Aqueous saffron extract and crocin, its active constituent, can protect rats from oxidative damages due to renal ischemia-reperfusion. ${ }^{18}$ Crocin is effective in prevention of acute liver damages induced by aflatoxin B1.44 It is likely that the anti-oxidant properties of SPE are a protective mechanism that prevents free radicals from being produced by cytochrome p-450 system. Antioxidants can neutralize free radicals in the environment and prevent the harmful effects of them. However, it is likely that the SPE increases supply of glutathione in the liver. 45 SPE might be a potential candidate agent against APAP-induced nephrotoxicity, but further studies are required to identify the side effects of the saffron petals as a rich source of antioxidants.

\section{References}

1. Bunchorntavakul C, Reddy KR. Acetaminophen-related hepatotoxicity. Clin Liver Dis 2013;17:587-607.

2. Pettie J, Dow M. Assessment and management of paracetamol poisoning in adults. Nurs Stand 2013;27:39-47.

3. Gulmez SE, Larrey D, Pageaux GP, et al. Transplantation for acute liver failure in patients exposed to NSAIDs or paracetamol (Acetaminophen). Drug Safety 2013;36:135-44. 
4. Antoine DJ, Dear JW, Lewis PS, et al. Mechanistic biomarkers provide early and sensitive detection of acetaminophen induced acute liver injury at first presentation to hospital. Hepatology 2013;58:777-87.

5. Xia J, Zhou XL, Zhao Y, et al. Roles of Lipoxin A4 in preventing paracetamolinduced acute hepatic injury in a rabbit model. Inflammation 2013;36:1431-9.

6. Pothiappan P, Muthuramalingam T, Sureshkumar R, et al. Paracetamol poisoning in a cat and its treatment. Ind $\mathrm{J}$ Vet Anim Sci Res 2014;43:388-9.

7. Cortinovis C, Pizzo F, Caloni F. Poisoning of dogs and cats by drugs intended for human use. Vet J 2015;203:52-8.

8. Maze GL, Lee M. Acute renal failure in an alcoholic patient taking therapeutic doses of acetaminophen. J Am Board Fam Pract 1998;11:410-3.

9. Saito C, Zwingmann C, Jaeschke H. Novel mechanisms of protection against acetaminophen hepatotoxicity in mice by glutathione and n-acetylcysteine. Hepatology 2010;51:246-54.

10. Hart SG, Beierschmitt WP, Wyand DS, et al. Acetaminophen nephrotoxicity in CD-1 mice. I. Evidence of a role for in situ activation in selective covalent binding and toxicity. Toxicol Appl Pharmacol 1994;126: 267-75.

11. Mazer M, Perrone J. Acetaminopheninduced nephrotoxicity: pathophysiology, clinical manifestations, and management. J Med Toxicol 2008;4:2-6.

12. Ncirciyanan S. Renal biochemistry and physiology: pathophysiology and analytical perspectives. Adv Clin Chem 1992;29:121.

13. Pasalic D, Marinkovic N, Feher-Turkovic L. Uric acid as one of the important factors in multifactorial disorders: facts and controversies. Biochem Med (Zagreb) 2012;22:63-75.

14. Ahmed MB, Khater MR. Evaluation of the protective potential of Ambrosia maritime extract on acetaminophen-induced liver damage. J Ethnopharmacol 2001;75:16974 .

15. Asadollahi A, Sarir H, Omidi A, Torbati MB. Hepatoprotective potential of prosopis farcta beans extracts against acetaminophen induced hepatotoxicity in Wister rats. Int J Prev Med 2014;5:1281-5.

16. Omidi A, Riahinia N, Montazer Torbati M, Behdani M. Hepatoprotective effect of Crocus sativus (saffron) petals extract pretreatment against acetaminophen toxicity in male Wistar rats. Avicenna J Phytomed 2014;5:330-6.

17. Golmohammadi F. Saffron and its farming, economic importance, export, medicinal characteristics and various uses in South Khorasan Province-East of Iran. Int J Farm
Allied Sci 2014;3-5:566-96.

18. Hosseinzadeh H, Sadeghnia HR, Ziaee T, Danaee A. Protective effect of aqueous saffron extract (Crocus sativus L.) and crocin, its active constituent, on renal ischemia-reperfusion: induced oxidative damage in rats. J Pharm Pharmaceut Sci 2005;8:387-93.

19. Ajami M, Eghtesadi S, Pazoki-Toroudi H, et al. Effect of crocus sativus on gentamicin induced nephrotoxicity. Biol Res 2010;43:83-90.

20. Malathi M, Devi DR, Hari BV. Crocus sativus Linn. A potential source for diverse therapeutic applications. Int J Pharm Sci Rev Res 2014;26.

21. Hosseinzadeh H, Younesi HM. Antinociceptive and anti-inflammatory effects of Crocus sativus L. stigma and petal extracts in mice. BMC Pharmacol 2002;2:1-8.

22. Hosseinzadeh H, Karimi GH, Niapoor M. Antidepressant effects of Crocus sativus stigma extracts and its constituents, crocin and safranal, in mice. Acta Hort 2004;650:435-45.

23. Vahidi H, Kamalinejad M, Sedaghati N. Antimicrobial properties of Crocus sativus L. Iran. J Pharmaceut Res 2002;1:33-5.

24. Nair SC, Pannikar B, Panikkar KR. Anti tumour activity of saffron (Crocus sativus). Cancer Lett 1991;57:109-14.

25. Abdullaev FI, Espinosa-Aguirre JJ. Biomedical properties of saffron and its potential use in cancer therapy and chemoprevention trials. Cancer Detect Prev 2004;28:426-32.

26. El-Daly ES. Protective effect of cystein and vitamin E, Crocus sativus and Nigella sativa extracts on cisplatin- induced toxicity in rats. J Pharm Belg 1998;53:87-95.

27. Zheng W, Wang SY. Antioxidant activity and phenolic compounds in selected herbs. J Agricult Food Chem 2001;49;516570.

28. Mortazavi SM, Moghaddam MK, Safi S, Salehi R. Saffron petals, a by-product for dyeing of wool fibers. Prog Color Colorants Coat 2012;5:75-84.

29. Omidi A, Torabi Z, Hassanpoorfard M, Zardast M. [Evaluation of protective effect of hydroalcoholic extract of Crocus sativus petals on preventing of gentamicin induced peliosis hepatis and hepatic telangiectasis in rats: short communication]. J Birjand Uni Med Sci 2013;19:45562. [Article in Persian [.

30. Kanakis CD, Tarantilis PA, Polissiou MG, et al. Antioxidant flavonoids bind human serum albumin. J Mol Struct 2006;798:6974.

31. Gil MI, Tomás-Barberán FA, Hess-Pierce B, Kader AA. Antioxidant capacities, phenolic compounds, carotenoids, and vitamin $\mathrm{C}$ contents of nectarine, peach, and plum cultivars from California. J Agric Food Chem 2002;50:4976-82.

32. Goli SAM, Mokhtari F, Rahimmalek M. Phenolic compounds and antioxidant activity from saffron (Crocus sativus L.). Petal J Agric Sci 2012;4:175-81.

33. Burtis CA, Ashwood ER, Bruns DE. Tietz textbook of clinical chemistry and molecular diagnostics. St. Louis: Elsevier Health Sciences; 2012.

34. Bancroft JD, Gamble M. Theory and practice of histological techniques. London: Churchill. Livingstone; 2002.

35. Zhao YL, Zhou GD, Yang HB, et al. Rhein protects against acetaminophen-induced hepatic and renal toxicity. Food Chem Toxicol 2011;49:1705-10.

36. Kelkar M, Cleves MA, Foster HR, et al. Acute and chronic acetaminophen use and renal disease: a case-control study using pharmacy and medical claims. J Manag Care Pharm 2012;18:234-46.

37. Jaeschke H, Gores GJ, Cederbaum AI, et al. Mechanisms of hepatotoxicity. Toxicol Sci 2002;65:166-76.

38. Bessems JG, Vermeulen NP. Paracetamol (acetaminophen)-induced toxicity: molecular and biochemical mechanisms, analogues and protective approaches. Crit Rev Toxicol 2001;31:55-138.

39. Ghosh J, Das J, Manna P. Sil PC. Acetaminophen induced renal injury via oxidative stress and TNF- $\alpha$ production: therapeutic potential of arjunolic acid. Toxicology 2010;268:8-18.

40. Abraham P, Kanakasabapathy I, Dian BJ. Propylthiouracil attenuates acetaminophen induced renal damage in the rat. Nephrology 2005;10:588-93.

41. Naghizadeh B, Boroushki MT, Mofidpour H. Protective effect of crocin against cisplatin nephrotoxicity in rats desert platinum. Iran J Basic Med Sci 2007;4:281-6.

42. Boroushaki MT, Sadeghnia HR. Protective effect of safranal against gentamicininduced nephrotoxicity in rat. Iran J Med Sci 2009;34:285-8.

43. Mohajeri D, Doustar Y, Rezaei A, MesgariAbbasi M. Hepatoprotective effect of ethanolic extract of Crocus sativus L. (Saffron) stigma in comparison with silymarin against rifampin induced hepatotoxicity in rats. J Res Zahedan Med Sci 2010;5:53-9.

44. Lin JK, Wang CJ. Protection of crocin dyes on the acute hepatic damage induced by aflatoxin Bland dimethyl nitrosamine in rats. Carcinogene 1986;7:595-9.

45. Scottluper ND. A review of plants used in the treatment of liver disease. Altern Med 1998;3:410-21. 